\title{
The Interaction Between Obesity and RAGE Polymorphisms on the Risk of Knee Osteoarthritis in Chinese Population
}

\author{
Zhu Han ${ }^{a}$ Qingpeng Liu ${ }^{a}$ Chongyi Sun ${ }^{a}$ Ying Lib \\ aDepartment of orthopedic, The 2nd affiliated hospital of Harbin medical university, Harbin; \\ bepartment of Interventional Radiology, The 2nd affiliated hospital of Harbin medical university, \\ Harbin
}

\section{Key Words}

Receptor for advanced glycation end products • Osteoarthritis • Polymorphisms • Obesity

\begin{abstract}
Background: The receptor for advanced glycation end products (RAGE) has been reported to relate to osteoarthritis (OA), however, the role of RAGE genetic variants in OA remains unknown. Method: A total of 233 patients with primary knee OA and 255 healthy volunteer were recruited. Three RAGE gene polymorphisms, namely, Gly82Ser (rs2070600). -374T/A (rs1800624) and 429T/C (rs1800625) were genotyped. Results: Of all three RAGE gene polymorphisms, only the genotype distributions and alleles frequencies of $82 \mathrm{G} / \mathrm{S}$ polymorphisms significantly differed between knee OA and control subjects. The presence of SS genotype and S allele of 82G/S we significantly higher in knee OA subjects than in controls (34.76\% vs. $19.61 \%$, P for trend $=0.004 ; 57.64 \%$ vs. $48.59 \%$, $P$ for trend $<0.001$, respectively). Multivariate logistic regression analysis showed a significantly increased risk for knee OA for the SS genotype compared with the AA genotype $(\mathrm{OR}=1.984,95 \% \mathrm{CI}: 1.238-3.181 ; \mathrm{P}=0.004)$. The adjusted $\mathrm{OR}$ for $\mathrm{S}$ allele carriage was significantly higher than $\mathrm{G}$ allele carriage $(\mathrm{OR}=1.440,95 \% \mathrm{CI}: 1.137-1.8231$, $\mathrm{P}=0.002$ ). Moreover, a significant multiplicative interaction was observed between $82 \mathrm{G} / \mathrm{S}$ polymorphisms with obesity (Pinteraction $=0.028$ ). Taking the non-obese 82GG genotype as references, the OR for OA in non-obese SS carriers was 2.537 (95\% CI 1.241-5.189, $P=0.001$ ). Notably, the OR in obese GS carriers was 2.304 (95\% CI: 1.218-4.357, $\mathrm{P}=0.009)$ and in obese SS was 3.392 (95\% CI: 1.672-6.885, P=0.001). The -374T/A and -429T/C did not show positive interaction with obesity and smoking status. Conclusion: The AGE 82G/S polymorphisms, in interaction with obesity, may determine the susceptibility of $O A$ in Chinese population.
\end{abstract}




\section{Introduction}

Osteoarthritis $(\mathrm{OA})$ is a common musculoskeletal diseaseamong the elderly, characterized by the degradation of articular cartilage and formation of abnormal bone (osteophyte) [1-3]. OA is a multifactorial disorder in which aging, hormonal and mechanical factors contribute to its onset and progression [4-6]. Recently, several studies have demonstrated the polymorphism in certain genes may be related to the pathogenesis of OA [7-10].

The receptor for advanced glycation end products (RAGE) is a member of the immunoglobulin superfamily of cell surface molecules and a receptor for advanced glycation end products (AGEs) [11,12]. AGE-RAGE interaction alters several cell functions through modulation of multiple intracellular signaling pathways, thus contribute in a variety of diseases, including inflammation and aging $[13,14]$. RAGE has been implicated in the pathogenesis of arthritis. RAGE is markedly expressed in joints with rheumatoid arthritis (RA) and amplifies the immune/inflammatory response in animal model; blockade of RAGE suppressed the histologic evidence of arthritis [15]. A previous study showed upregulated chondrocyte expression of the RAGE in OA cartilage, and RAGE signaling promote inflammation-associated chondrocyte hypertrophy, suggesting that RAGE signaling has a potential to contribute to OA [16].

To date, several functional single nucleotide polymorphismshave (SNPs) been identified in RAGE gene, among which the Gly82Ser (rs2070600, 244G>A). -374T/A (rs1800624) and $-429 \mathrm{~T} / \mathrm{C}$ (rs1800625) were mostly studied. The functional Gly82Ser occurs in the ligandbinding V domain of RAGE and affects ligand affinity while the -374T/A and-429T/C are located in the promoter region and have been shown to increase reporter gene expression [17-20]. Pervious studies reported positive associations between the variants of RAGE gene and chronic inflammation [21,22]. However, no study regarding the role of RAGE genetic variants in $\mathrm{OA}$ was reported. In present study, we performed a case-control study in knee OA subjects in Chinese cohorts to explorer the association of RAGE polymorphisms and risk of knee OA. Meanwhile, we studied the potential interaction between RAGE gene polymorphisms and other factors associated with $\mathrm{OA}$, such as obesity and smoking status, in determining the susceptibility of OA.

\section{Materials and Methods}

\section{Patients}

A total of 233 patients with primary knee OA were recruited from Feb 2007 to Dec 2011. The diagnosis of knee OA was based on the American College of Rheumatology criteria [23], 255 healthy volunteer were enrolled as controls. Both $\mathrm{OA}$ and control groups were interviewed to obtain demographic data and all of established risk factors. In the study, other etiologies causing knee diseases such as inflammatory arthritis (rheumatoid, polyarthritic, or autoimmune disease), posttraumatic or post-septic arthritis, skeletal dysplasia or developmental dysplasia were excluded from OA group. All the control never had any signs or symptoms of arthritis or joint diseases (pain, swelling, tenderness, or restriction of movement). The clinical characteristics of all enrolled sujects, including age, sex, body mass index (BMI), diabetes mellitus (DM) smoke status, bone fracture history, knee activity and regular excise were recorded. Obesity was defined as $\mathrm{BMI}>30 \mathrm{~kg} / \mathrm{M}^{2}$. The study was approved by the ethics review committee of our hospital and written informed consent was obtained from all participants.

\section{Genotyping}

RAGE genotyping. The protocol for genomic DNA extraction was described in a previous study. A PCRRFLP assay was used to determine the RAGE polymorphisms. PCR was done in $20 \mu \mathrm{L}$ reaction mixtures containing $1.625 \mathrm{mmol} / \mathrm{L} \mathrm{MgCl} 2,0.14 \mathrm{mmol} / \mathrm{L}$ deoxynucleotide triphosphates, 1 unit of Taq polymerase (MBI Fermentas), $2 \mu \mathrm{L}$ of 10× PCR buffer (MBI Fermentas), 200 ng genomic DNA and $0.25 \mu \mathrm{mol} / \mathrm{L}$ of each primer (forward, 5'-GTAAGCGGGGCTCCTGTTGCA-3'; reverse, 5'-GGCCAAGGCTGGGGTTGAAGG-3' [15]), (forward, 5'-GTAAGCGGGGCTCCTGTTGCA-3'; reverse, 5'-GGCCAAGGCTGGGGTTGAAGG-3' [15]), (forward, 
Table 1. The demographic and clinical characteristics of all subjects in the study.

\begin{tabular}{llll}
\hline Variables & Cases $(\mathrm{n}=275)$ & Control $(\mathrm{n}=283)$ & $\mathrm{P}$ \\
\hline Age (years) & $63.5 \pm 6.4$ & $63.6 \pm 6.1$ & 0.871 \\
Female (\%) & $169(61.5 \%)$ & $177(62.5 \%)$ & 0.429 \\
Obesity & $174(62.27 \%)$ & $147(51.94 \%)$ & 0.003 \\
DM & $98(35.63 \%)$ & $69(24.38 \%)$ & 0.002 \\
Smoking (\%) & $125(45.45 \%)$ & $130(45.93 \%)$ & 0.43 \\
OA family history & $109(39.1 \%)$ & $114(40.3 \%)$ & 0.472 \\
History of labor work $(\%)$ & $114(41.4 \%)$ & $120(42.4 \%)$ & 0.444 \\
\hline
\end{tabular}

5'-GTAAGCGGGGCTCCTGTTGCA-3'; reverse, 5'-GGCCAAGGCTGGGGTTGAAGG-3' [15]). After an initial denaturation at $95^{\circ} \mathrm{C}$ for $5 \mathrm{~min}$, the DNA was amplified by 35 cycles of $94^{\circ} \mathrm{C}$ for $30 \mathrm{~s}, 62^{\circ} \mathrm{C}$ for $40 \mathrm{~s}$, and $72^{\circ} \mathrm{C}$ for $45 \mathrm{~s}$, with a final elongation at $72^{\circ} \mathrm{C}$ for $10 \mathrm{~min}$. The 397 -bp PCR products were digested by the restriction enzyme AluI, 5 units for $16 \mathrm{~h}$ at $37^{\circ} \mathrm{C}$, followed by electrophoresis on a $2 \%$ agarose gel. The digestion revealed fragments of length 249, 123, and $26 \mathrm{bp}$ for the wild-type Gly82 allele and 181, 123, 67, and $26 \mathrm{bp}$ for the variant Ser 82 allele. About $10 \%$ of the samples were randomly selected to do the repeated assays, and the results were $100 \%$ concordant. Two researchers, blinded to the clinical data, scored the genotypes independently.

\section{Statistical analyses}

Quantitative variables e.g. age between OA subjects and controls were shown as compared using Student's t test, and qualitative variables, e.g. genotype and allele frequencies, et al., were compared using the chi-square test or Fisher's exact test. The power calculations were performed as previously described [24]. Logistic regression was used to test the associations between disease status and genetic polymorphisms of OPN gene after adjusting for relevant covariates. The $\mathrm{D}^{\prime}$ value and $\mathrm{r} 2$ for the studied 3 SNPs were calculated with the SHEsis software [25]. The interaction between smoking and RAGE SNPs were estimated via multiplicative interaction term and the stratified analysis of the effect of SNPs on OA by smoking and obesity status. The Statistical Package of the Social Sciences software version 16.0 (SPSS Inc., Chicago, IL) was used for statistical analyses. A 2-sided $\mathrm{P}<0.05$ was considered to be significant.

\section{Results}

Table 1 shows demographic and clinical characteristics of all subjects in the study. There were no significant differences in sex, age, Smoking, OA family history, History of labor work between knee OA cases and controls. Obesity, which is one of the risk factor of knee OA, was significantly higher in the $\mathrm{OA}$ patient group than in controls $(\mathrm{P}<0.001)$.

Table 2 described the genotype distributions and allele frequencies of RAGE polymorphisms in knee $\mathrm{OA}$ and control subjects. The genotype frequencies for all polymorphisms in controls did not differ significantly from those expected under HardyWeinberg equilibrium (all $\mathrm{P}>0.05$ ). There were no significant differences of genotype distributions and alleles frequencies of $-429 \mathrm{~T} / \mathrm{C}$ and $-374 \mathrm{~T} / \mathrm{A}$ between knee OA subjects and control subjects ( $\mathrm{P}$ for trend $=0.347$ and 0.460 , respectively, Table 2 ). However, genotype frequencies and allele frequencies at $82 \mathrm{G} / \mathrm{S}$ polymorphisms significantly differed between $\mathrm{OA}$ and control subjects. The presence of SS genotype of $82 \mathrm{G} / \mathrm{S}$ was significantly higher in knee OA subjects than in controls $(35.27 \%$ vs. $22.61 \%$, P for trend $=0.002)$. Accordingly, the $82 \mathrm{~S}$ allele frequency was higher in $\mathrm{OA}$ patients than controls $(57.64 \%$ vs. $48.59 \%$, $\mathrm{P}<0.001)$. Multivariate logistic regression analysis showed a significantly increased risk for knee OA for the SS genotype of $82 \mathrm{G} / \mathrm{S}$ compared with the AA genotype (OR=1.984, 95\% CI: 
Table 2. Described the genotype distributions and allele frequencies of RAGE polymorphisms in knee OA and control subjects.

\begin{tabular}{|c|c|c|c|c|c|c|c|c|c|c|}
\hline & & \multirow{2}{*}{$\frac{\mathrm{OA}}{\mathrm{N}}$} & \multicolumn{3}{|c|}{ Control } & \multirow[t]{2}{*}{ adjusted $\mathrm{OR}$} & \multicolumn{2}{|c|}{$95 \% \mathrm{Cl}$} & \multirow[t]{2}{*}{$\mathrm{X} 2$} & \multirow[t]{2}{*}{ adjusted P } \\
\hline \multicolumn{2}{|l|}{ RAGE } & & $\%$ & $\mathrm{~N}$ & $\%$ & & & & & \\
\hline \multirow[t]{5}{*}{$-374 \mathrm{~T} / \mathrm{A}$} & TT & 84 & $30.55 \%$ & 71 & $25.09 \%$ & 1.000 & & & & \\
\hline & TA & 120 & $43.64 \%$ & 131 & $46.29 \%$ & 0.774 & 0.518 & 1.157 & 1.563 & 0.211 \\
\hline & $\mathrm{AA}$ & 71 & $25.82 \%$ & 81 & $28.62 \%$ & 0.741 & 0.473 & 1.160 & 1.719 & 0.190 \\
\hline & $\mathrm{T}$ & 288 & $52.36 \%$ & 273 & $48.23 \%$ & 1.000 & & & & \\
\hline & A & 262 & $47.64 \%$ & 293 & $51.77 \%$ & 0.848 & 0.670 & 1.072 & 1.904 & 0.168 \\
\hline \multirow[t]{5}{*}{$-429 \mathrm{~T} / \mathrm{C}$} & TT & 59 & $25.00 \%$ & 69 & $24.38 \%$ & 1.000 & & & & \\
\hline & $\mathrm{TC}$ & 118 & $50.00 \%$ & 155 & $54.77 \%$ & 0.890 & 0.584 & 1.358 & 0.291 & 0.589 \\
\hline & $\mathrm{CC}$ & 59 & $25.00 \%$ & 59 & $20.85 \%$ & 1.169 & 0.709 & 1.930 & 0.375 & 0.540 \\
\hline & $\mathrm{T}$ & 236 & $50.00 \%$ & 293 & $51.77 \%$ & 1.000 & & & & \\
\hline & C & 236 & $50.00 \%$ & 273 & $48.23 \%$ & 1.073 & 0.841 & 1.370 & 0.321 & 0.571 \\
\hline \multirow[t]{5}{*}{$82 \mathrm{G} / \mathrm{S}$} & GG & 55 & $20.00 \%$ & 72 & $25.44 \%$ & 1.000 & & & & \\
\hline & GS & 123 & $44.73 \%$ & 147 & $51.94 \%$ & 1.095 & 0.716 & 1.675 & 0.177 & 0.674 \\
\hline & SS & 97 & $35.27 \%$ & 64 & $22.61 \%$ & 1.984 & 1.238 & 3.181 & 8.176 & 0.004 \\
\hline & G & 233 & $42.36 \%$ & 291 & $51.41 \%$ & 1.000 & & & & \\
\hline & $\mathrm{S}$ & 317 & $57.64 \%$ & 275 & $48.59 \%$ & 1.440 & 1.137 & 1.823 & 9.172 & 0.002 \\
\hline
\end{tabular}

Table 3. The associations between the RAGE haplotypes and knee OA risk.

\begin{tabular}{ccclllll}
\hline -374T/A & $-429 \mathrm{~T} / \mathrm{C}$ & $82 \mathrm{G} / \mathrm{S}$ & Case(freq) & Control(freq) & Chi2 & $\mathrm{P}$ & Odds Ratio [95\%Cl] \\
\hline $\mathrm{A}$ & $\mathrm{C}$ & $\mathrm{S}$ & $102.98(0.201)$ & $172.28(0.176)$ & 1.59 & 0.234 & $1.195[0.901 \sim 1.674]$ \\
$\mathrm{A}$ & $\mathrm{C}$ & $\mathrm{G}$ & $33.92(0.064)$ & $106.49(0.143)$ & 7.53 & 0.0061 & $0.572[0.251 \sim 0.895]$ \\
$\mathrm{A}$ & $\mathrm{T}$ & $\mathrm{G}$ & $62.5(0.127)$ & $115.45(0.224)$ & 0.31 & 0.647 & $1.094[0.777 \sim 1.598]$ \\
$\mathrm{T}$ & $\mathrm{C}$ & $\mathrm{G}$ & $70.11(0.146)$ & $15.53(0.142)$ & 0.38 & 0.539 & $0.909[0.611 \sim 1.529]$ \\
$\mathrm{T}$ & $\mathrm{T}$ & $\mathrm{G}$ & $49.14(0.113)$ & $85.75(0.093)$ & 0.006 & 0.972 & $0.985[0.683 \sim 1.412]$ \\
$\mathrm{T}$ & $\mathrm{C}$ & $\mathrm{S}$ & $115.27(0.223)$ & $107.83(0.107)$ & 0.735 & 0.0232 & $2.176[1.252 \sim 2.671]$ \\
\hline
\end{tabular}

1.238-3.181; $\mathrm{P}=0.004$ ) after adjustment with sex, age, BMI, smoke status, history of labor work, regular exercise and knee activity. The adjusted OR for $\mathrm{S}$ allele carriage was significantly higher than $\mathrm{G}$ allele carriage (OR=1.440, 95\% CI: 1.137-1.8231, P=0.002). In order to testify this difference is real or just by chance, we performed power calculation. Our date showed that the difference of $82 \mathrm{G} / \mathrm{S}$ between $\mathrm{OA}$ and controls had acceptable power values (power values $=0.85$ between $G G$ and SS genotype carriers and $=0.86$ between $G$ and $S$ allele carriers). Besides $82 \mathrm{G} / \mathrm{S}$ polymorphisms, multivariate logistic regression analysis also showed that obesity and DM were risk factor for the occurrence of $\mathrm{OA}$ in this study $(\mathrm{OR}=1.754,95 \%$ $\mathrm{CI}: 1.215-3.154, \mathrm{P}=0.014$ and $\mathrm{OR}=1.584,95 \% \mathrm{CI}: 1.132-3.545, \mathrm{P}=0.022$, respectively).

The associations between the RAGE haplotypes and knee OA risk were analyzed in this study. The $\mathrm{D}^{\prime}$ value and $\mathrm{r} 2$ for the studied 3 SNPs were calculated with the SHEsis software [21]. All 3 SNPS were in strong $L D$ (all $D^{\prime}>0.8$ ). The estimated haplotype frequencies of the RAGE SNPs are shown in Table 3. The haplotype $A_{-374} C_{-429} G_{82}$ represented protective effect for developing knee $\mathrm{OA}(\mathrm{OR}=0.572, \mathrm{P}=0.0061)$. In contrast, the $\mathrm{T}_{-374} \mathrm{C}_{-429} \mathrm{~S} 82$ showed a higher risk for developing $\mathrm{OA}(\mathrm{OR}=2.176, \mathrm{P}=0.0129$, Table 3$)$.

We further analyzed the interaction between the 82G/S RAGE polymorphisms and smoking status in determining the risk of OA. Table 4 showed the $82 \mathrm{G} / \mathrm{S}$ polymorphisms did not have a positive interaction with smoke status (all FDR- $P_{\text {interaction }}=0.236$, table 4 ) for OA risk. We next analyzed the interaction between RAGE and obesity status with the risk 
Table 4. The interaction between $82 \mathrm{G} / \mathrm{S}$ polymorphisms with smoking status and obesity for the susceptibility to $\mathrm{OA}$.

\begin{tabular}{|c|c|c|c|c|c|c|c|c|c|}
\hline \multicolumn{2}{|c|}{ Genotype } & \multirow{2}{*}{$\begin{array}{c}\text { Factor } \\
\text { Non-Smokers }\end{array}$} & \multirow{2}{*}{$\frac{\mathrm{OA}}{35}$} & \multirow{2}{*}{$\begin{array}{r}\text { Controls } \\
36\end{array}$} & \multirow{2}{*}{$\frac{\mathrm{OR}}{1}$} & \multicolumn{2}{|c|}{$95 \% \mathrm{Cl}$} & \multirow[t]{2}{*}{$P$} & \multirow[t]{2}{*}{ FDR-P Pinteration } \\
\hline $82 \mathrm{G} / \mathrm{S}$ & GG & & & & & & & & \\
\hline & GS & Non-Smokers & 60 & 76 & 0.81203 & 0.456766 & 1.443611 & 0.477879 & \\
\hline & SS & Non-Smokers & 55 & 41 & 1.379791 & 0.744887 & 2.555854 & 0.305475 & 0.236 \\
\hline & GG & Smokers & 20 & 36 & 0.571429 & 0.278752 & 1.171403 & 0.125117 & \\
\hline & GS & Smokers & 63 & 71 & 0.912676 & 0.513152 & 1.623257 & 0.755752 & \\
\hline & SS & Smokers & 42 & 23 & 1.878261 & 0.942867 & 3.741634 & 0.071757 & \\
\hline \multirow[t]{3}{*}{$82 \mathrm{G} / \mathrm{S}$} & GG & Non-obese & 19 & 37 & 1.00 & & & & \\
\hline & GS & Non-obese & 39 & 66 & 1.151 & 0.583 & 2.272 & 0.686 & 0.012 \\
\hline & SS & Non-obese & 43 & 33 & 2.537 & 1.241 & 5.189 & 0.010 & \\
\hline
\end{tabular}

of OA. We found that there was a positive interaction only between the $82 \mathrm{G} / \mathrm{S}$ and obesity (FDR- $P_{\text {interaction }}=0.0122$ ). Taking the non-obese $82 \mathrm{GG}$ genotype as references, the $\mathrm{OR}$ for OA in non-obese SS carriers was 2.537, 95CI 1.241-5.189, $\mathrm{P}=0.001$ ). Notably, the OR in obese GS carriers was 2.019 ( $\mathrm{P}=0.028$ ); the OR in obese SS carriers was 3.392 (95\% CI: 1.671$6.885, \mathrm{P}=0.001$ ). The $-374 \mathrm{~T} / \mathrm{A}$ and $-429 \mathrm{~T} / \mathrm{C}$ did not show positive interaction with obesity and smoking status (data not shown).

\section{Discussion}

In this study, we investigated whether 3 RAGE SNPs, interacting with smoking status and obesity, influence the susceptibility of OA in a Chinese cohort. Our results showed that only the $82 \mathrm{G} / \mathrm{S}$ had a closely association with $\mathrm{OA}$ risk by multiple regression analyses. The 82SS carriage tends to have a 2.3 times higher risk to develop OA. There was no interaction between RAGE and smoke in determining the OA risk. In contrast, obesity status significantly influenced the effect of RAGE gene polymorphisms on the susceptibility of OA. With non-obese 82GG genotype as references, the $\mathrm{OR}$ for $\mathrm{OA}$ in obese $82 \mathrm{GG}$ carriers was $3.432(\mathrm{P}=0.005)$; in obese 82GS was 4.141 and in obese 82SS reached $6.812(\mathrm{P}<0.001)$. To the best of knowledge, this is the first study regarding the interaction between RAGE SNPs and obesity status in OA susceptibility. Our finding highlights the importance of obesity in determining the genetic risk for OA.

Recent studies reported the RAGE 82G/S polymorphism results in the enhancement of pro-inflammatory mechanisms in immune/inflammatory diseases [26]. Soluble RAGE (sRAGE) is well accepted as a protective factor to inflammation [27]. A previous study showed the sRAGE concentrations were highest in subjects with the G/G genotype, medium in those with the G/S and lowest in S/S genotype carriers [22]. sRAGE levels were reported to be significantly lower in OA patients compared with controls, and sRAGE levels in plasma and synovial fluid also decreased significantly as the disease severity increased [28]. A remarkable association of the G82S variant with elevated serum CRP levels in the Chinese Han population with coronary heart disease, implying that the prevalence of RAGE 82S allelic variation may influence vascular inflammation level [29]. In this study, we found had higher presence of 82SS genotype in OA subjects than in controls, we postulated that might be due to the higher inflammation level in OA patients than controls. Unfortunately, in this study, we did not detect the plasma sRAGE level (ideally, the sRAGE level in the synovial fluid) to 
better document the association between the RAGE polymorphisms and OA. This is a major limitation of this study.

Two studies reported higher GG distribution (between 47\%-63\%GG prevalence) in Chinese cohorts $[18,30]$, However, our study showed a lower GG frequencies (between $20 \%$ $26 \%$ ). In contrast, the SS genotype rate in our study was higher in our study. Our date showed that the difference of $82 \mathrm{G} / \mathrm{S}$ between $\mathrm{OA}$ and controls had acceptable power values $(>0.8)$. Although all the participants were Chinese, their geographic living area and environmental factors were quite different. We postulate the disparities of gene distribution might be due to the geographic and environmental factors.

Obesity is closely associated with low-grade inflammation. The Gly82Ser polymorphism was reported to be related to RAGE expression and is also involved in inflammatory response. [31] Particularly in obese subjects, S/S carriers showed significantly higher concentrations of AGEs and $C$ reaction protein (CRP) than $G$ allele carriers. RAGE is involved in the development of obesity and insulin resistance [32]. The association between obesity and insulin resistance as well as DM has been documented previously [33]. In our study, the OA patients had a higher rate of DM and obesity. Multiple-variants analysis showed that both DM and obesity were risk factors for $\mathrm{OA}$.

The association between obesity and knee osteoarthritis, and specifically the role of obesity as a risk factor for knee osteoarthritis has been well documented [34-36]. A systematic review and meta-analysis examined 36 papers reporting on BMI and found that all studies demonstrated obesity and being overweight to be risk factors for knee osteoarthritis [37]. The potential mechanisms to link obesity and knee osteoarthritis, as both a biomechanical and metabolic condition are strongly linked. It has been established that weight loss for obese patients with knee OA is clinically beneficial. In present study, the mean BMI was significantly higher in OA patient than in controls. The positive interaction between RAGE SNPs and obesity suggest that reduction of body weight might reduce the genetically determined risk for OA.

\section{References}

1 Corti MC, Rigon C: Epidemiology of osteoarthritis: prevalence, risk factors and functional impact. Aging Clin Exp Res 2003;15:359-363.

2 Blanco FJ, Lopez-Armada MJ, Maneiro E: Mitochondrial dysfunction in osteoarthritis. Mitochondrion 2004;4:715-728.

3 Kjaer NK, Lorenzen T: Osteoarthritis, the most common joint problem. Ugeskr Laeger 2005;167:44574458.

4 Dequeker J, Aerssens J, Luyten FP: Osteoarthritis and osteoporosis: clinical and research evidence of inverse relationship. Aging Clin Exp Res 2003;15:426-439.

5 Crepaldi G, Punzi L: Aging and osteoarthritis. Aging Clin Exp Res 2003;15:355-358.

6 Elbaz A, Debbi EM, Segal G, Haim A, Halperin N, Agar G, Mor A, Debi R: Sex and body mass index correlate with Western Ontario and McMaster Universities Osteoarthritis Index and quality of life scores in knee osteoarthritis. Arch Phys Med Rehabil 2011;92:1618-1623.

7 Loughlin J: Genetic indicators and susceptibility to osteoarthritis. Br J Sports Med 2011;45:278-282.

-8 Jotanovic Z, Etokebe GE, Mihelic R, Kaarvatn MH, Mulac-Jericevic B, Tijanic T, Balen S, Sestan B, Dembic Z: IL1B -511(G>A) and IL1RN (VNTR) allelic polymorphisms and susceptibility to knee osteoarthritis in Croatian population. Rheumatol Int 2012;32:2135-2141.

-9 Honsawek S, Deepaisarnsakul B, Tanavalee A, Yuktanandana P, Bumrungpanichthaworn P, Malila S, Saetan $\mathrm{N}$ : Association of the IL-6 -174G/C gene polymorphism with knee osteoarthritis in a Thai population. Genet Mol Res 2011;10:1674-1680.

10 Lee SJ, Kim MJ, Kee SJ, Song SK, Kweon SS, Shin MH, Park DJ, Park YW, Lee SS, Kim TJ: Association study of the candidate gene for knee osteoarthritis in Koreans. Rheumatol Int 2011.

11 Schmidt AM, Yan SD, Yan SF, Stern DM: The biology of the receptor for advanced glycation end products and its ligands. Biochim Biophys Acta 2000;1498:99-111.

12 Lindsey JB, Cipollone F, Abdullah SM, McGuire DK: Receptor for advanced glycation end-products (RAGE) and soluble RAGE (sRAGE): cardiovascular implications. Diab Vasc Dis Res 2009;6:7-14. 
13 Ramasamy R, Vannucci SJ, Yan SS, Herold K, Yan SF, Schmidt AM: Advanced glycation end products and RAGE: a common thread in aging, diabetes, neurodegeneration, and inflammation. Glycobiology 2005;15:16R-28R.

14 Ramasamy R, Yan SF, Schmidt AM: RAGE: therapeutic target and biomarker of the inflammatory response-the evidence mounts. J Leukoc Biol 2009;86:505-512.

-15 Sunahori K, Yamamura M, Yamana J, Takasugi K, Kawashima M, Makino H: Increased expression of receptor for advanced glycation end products by synovial tissue macrophages in rheumatoid arthritis. Arthritis Rheum 2006;54:97-104.

-16 Cecil DL, Johnson K, Rediske J, Lotz M, Schmidt AM, Terkeltaub R: Inflammation-induced chondrocyte hypertrophy is driven by receptor for advanced glycation end products. J Immunol 2005;175:8296-8302.

-17 Kokkola R, Andersson A, Mullins G, Ostberg T, Treutiger CJ, Arnold B, Nawroth P, Andersson U, Harris RA, Harris HE: RAGE is the major receptor for the proinflammatory activity of HMGB1 in rodent macrophages. Scand J Immunol 2005;61:1-9.

-18 Li K, Zhao B, Dai D, Yao S, Liang W, Yao L, Yang Z: A functional p.82G >S polymorphism in the RAGE gene is associated with multiple sclerosis in the Chinese population. Mult Scler 2011;17:914-921.

19 Pettersson-Fernholm K, Forsblom C, Hudson BI, Perola M, Grant PJ, Groop PH: The functional -374 T/A RAGE gene polymorphism is associated with proteinuria and cardiovascular disease in type 1 diabetic patients. Diabetes 2003;52:891-894.

20 Picheth G, Heidemann M, Pedrosa FO, Chautard-Freire-Maia EA, Costantini CO, da Rocha Martinez TL, de Souza EM: The $-429 \mathrm{~T}>\mathrm{C}$ polymorphism of the receptor for advanced glycation end products (RAGE) is associated with type 1 diabetes in a Brazilian population. Clin Chim Acta 2007;383:163-164.

21 Dabritz J, Friedrichs F, Weinhage T, Hampe J, Kucharzik T, Lugering A, Broeckel U, Schreiber S, Spieker T, Stoll M: The functional -374T/A polymorphism of the receptor for advanced glycation end products may modulate Crohn's disease. Am J Physiol Gastrointest Liver Physiol 2011;300:G823-832.

-22 Jang Y, Kim JY, Kang SM, Kim JS, Chae JS, Kim OY, Koh SJ, Lee HC, Ahn CW, Song YD: Association of the Gly82Ser polymorphism in the receptor for advanced glycation end products (RAGE) gene with circulating levels of soluble RAGE and inflammatory markers in nondiabetic and nonobese Koreans. Metabolism 2007;56:199-205.

-23 Altman R, Asch E, Bloch D, Bole G, Borenstein D, Brandt K, Christy W, Cooke TD, Greenwald R, Hochberg M: Development of criteria for the classification and reporting of osteoarthritis. Classification of osteoarthritis of the knee. Diagnostic and Therapeutic Criteria Committee of the American Rheumatism Association. Arthritis Rheum 1986;29:1039-1049.

24 Chen B, Wilkening S, Drechsel M, Hemminki K: SNP_tools: A compact tool package for analysis and conversion of genotype data for MS-Excel. BMC Res Notes 2009;2:214.

$\checkmark 25$ Shi YY, He L: SHEsis, a powerful software platform for analyses of linkage disequilibrium, haplotype construction, and genetic association at polymorphism loci. Cell Res 2005;15:97-98.

-26 Baiguera S, Fioravanzo L, Grandi C, Di Liddo R, Parnigotto PP, Folin M: Involvement of the receptor for advanced glycation-end products (RAGE) in beta-amyloid-induced toxic effects in rat cerebromicrovascular endothelial cells cultured in vitro. Int J Mol Med 2009;24:9-15.

27 Wautier JL, Grossin N: sRAGE and esRAGE. Diabetes Metab 2008;34:631.

28 Chayanupatkul M, Honsawek S: Soluble receptor for advanced glycation end products (sRAGE) in plasma and synovial fluid is inversely associated with disease severity of knee osteoarthritis. Clin Biochem 2010;43:1133-1137.

29 Gao J, Shao Y, Lai W, Ren H, Xu D: Association of polymorphisms in the RAGE gene with serum CRP levels and coronary artery disease in the Chinese Han population. J Hum Genet 2010;55:668-675.

-30 Peng WH, Lu L, Wang LJ, Yan XX, Chen QJ, Zhang Q, Zhang RY, Shen WF: RAGE gene polymorphisms are associated with circulating levels of endogenous secretory RAGE but not with coronary artery disease in Chinese patients with type 2 diabetes mellitus. Arch Med Res 2009;40:393-398.

31 Kim OY, Jo SH, Jang Y, Chae JS, Kim JY, Hyun YJ, Lee JH: G allele at RAGE SNP82 is associated with proinflammatory markers in obese subjects. Nutr Res 2009;29:106-113.

-32 Leuner B, Max M, Thamm K, Kausler C, Yakobus Y, Bierhaus A, Sel S, Hofmann B, Silber RE, Simm Al: RAGE influences obesity in mice. Effects of the presence of RAGE on weight gain, AGE accumulation, and insulin levels in mice on a high fat diet. Z Gerontol Geriatr 2012;45:102-108.

33 Westphal SA: Obesity, abdominal obesity, and insulin resistance. Clin Cornerstone 2008;9:23-29; discussion 30-21.

34 Lee R, Kean WF: Obesity and knee osteoarthritis. Inflammopharmacology 2012;20:53-58.

35 Pecina M: Obesity and osteoarthritis of the knee. Lijec Vjesn 2009;131:162-163; author reply 163-164.

-36 Ghroubi S, Elleuch H, Guermazi M, Kaffel N, Feki H, Abid M, Baklouti S, Elleuch MH: Abdominal obesity and knee ostheoarthritis. Ann Readapt Med Phys 2007;50:661-666.

37 Blagojevic M, Jinks C, Jordan KP: The influence of consulting primary care on knee pain in older people: a prospective cohort study. Ann Rheum Dis 2008;67:1702-1709. 